\title{
Validity and reliability of the Arabic dyscalculia test in diagnosing Egyptian dyscalculic school-age children
}

\author{
R. M. Abdou, N. H. Hamouda* and A. M. Fawzy
}

\begin{abstract}
Background: Mathematical skills have an important role in progress of the educational level of nations. Unfortunately, there are still some pupils in school with normal intellectual function, but they have different degrees of mathematical disabilities that really can fall apart their whole life.

Dyscalculia is called number blindness. It is the name given to the condition that affects our ability to acquire arithmetical skills. In the Arabic language, there is a deficiency in tools for diagnosis of dyscalculia, so we conducted this study to formulate a test suitable for diagnosis of dyscalculia in Egyptian children via translation and modification of an American test (TOMA 3 test).

Results: The modified test was highly significant in discriminating dyscalculic from non-dyscalculic Egyptian pupils regarding all items of the test.

Conclusion: The Arabic version of TOMA-3 is valid and reliable for diagnosis of dyscalculia in Egyptian school-age children.
\end{abstract}

\section{Background}

Mathematical knowledge is one of the foundations of human cognitive and creative development [1]. However, some individuals commonly have some type of difficulty in acquiring basic mathematical concepts. This difficulty starts right at the base, and because it is not taken seriously, it escalates resulting in dyscalculia.

Dyscalculia is a specific learning disability affecting normal development of school-level arithmetic skills that results from specific neurocognitive dysfunction [2]. It is a brain-based condition with a familial-genetic predisposition that makes it hard to make sense of numbers and mathematics concepts [3]. The term dyscalculia dates back to at least 1949. It comes from Greek and Latin and means "counting badly" [4]. The two other common terms are "Mathematics Disorder" and "Mathematical Disabilities" (an educational term primarily used in America) [5]. Five to 10\% of school-age children

\footnotetext{
* Correspondence: nesrinehazem@gmail.com

Faculty of Medicine, Alexandria University, Champillion str. Azarita, 21563 Alexandria, Egypt
}

\section{Springer Open}

have some form of cognitive deficit that limits their aptitude to acquire knowledge and understand fundamental ideas in numeracy [6].

Developmental dyscalculia (DD) could be divided into primary and secondary DD with different underlying profiles and causes [7]. Primary DD is characterized by a severe deficit in numerical or arithmetic functioning, caused by different underlying biological factors [8] including congenital factor [9], and brain developmental factor (dyscalculic people have not developed the intraparietal sulcus that is linked to the all arithmetic processing as much as typical learners) [10].

Secondary DD denotes impaired numerical capacity that can be explained by non-numerical impairments as working memory processes dysfunction [11], visualspatial attention deficits [12], and low socio-economic status [13].

Twenty to $60 \%$ of all persons with dyscalculia also have comorbid other conditions [14]. The most common cognitive disabilities that often associated with DD are

(c) The Author(s). 2020 Open Access This article is licensed under a Creative Commons Attribution 4.0 International License, which permits use, sharing, adaptation, distribution and reproduction in any medium or format, as long as you give appropriate credit to the original author(s) and the source, provide a link to the Creative Commons licence, and indicate if changes were made. The images or other third party material in this article are included in the article's Creative Commons licence, unless indicated otherwise in a credit line to the material. If material is not included in the article's Creative Commons licence and your intended use is not permitted by statutory regulation or exceeds the permitted use, you will need to obtain permission directly from the copyright holder. To view a copy of this licence, visit http://creativecommons.org/licenses/by/4.0/. 
dyslexia [15] and Attention Deficit Hyperactivity Deficit (ADHD) [16].

Mathematical skills and concepts are used everywhere from the kitchen to the playground and the workplace. In fact, people with dyscalculia struggle from their difficulties for years before they undergo proper assessment. Failure to identify dyscalculia early enough for early intervention leads to a bad impact on our children's daily activities that require adequate mathematical ability.

Successful diagnosis of dyscalculia is performed by personal, familial, scholastic developmental history [17], general examination, psychometric evaluation [18], working memory task [19], and standardized tests for evaluation of arithmetic ability [20], to determine how dyscalculic children can do basic calculations, reasoning quantitative and numerical fact computation.

In the English language, there are many examples of tests that can help in diagnoses of DD, such as the Wechsler Individual Achievement Test [21], the Key Math 3 Diagnostic Assessment [22], and the Dyscalculia Screener Test [23]. On the other hand, in the Arabic language, there is a deficiency in tools for diagnosis of dyscalculia, hence, the urgent societal need to develop a standardized Arabic test of mathematical abilities to help in early detection of failing learners.

The Test of Mathematical Abilities-Third Edition (TOMA-3) is an easily administered, norm-referenced, assessment tool used to identify, describe, and quantify mathematical deficits in school-age children. It can determine the magnitude of any mathematical problems, but it is available in only the English language [24].

Therefore, the current study aimed to formulate a modified Arabic version of the Test of Mathematical Abilities-Third Edition (TOMA-3) to suit Egyptian children and test its validity and reliability as a diagnostic tool for dyscalculia, which would guide in the early recognition of arithmetic difficulties and provide a basis for the planning of effective treatment.

\section{Methods}

\section{Subjects}

This study included 170 Egyptian school-age children who were divided into 2 groups. Group 1 consisted of 100 normal school-age children of both sexes between the ages of 8 and 19 years old who were used as controls for comparative study. Group 2 included 70 children with dyscalculia of both sexes between the ages of 8 and 19 years old. Exclusion criteria included low intellectual functions and hearing or visual impairment.

\section{Methods}

All candidates were subjected to full history taking with stress upon consanguinity and similar conditions in family, history of delayed language development, time of discovery of arithmetic difficulties, and any comorbid condition such as ADHD and dyslexia. Auditory and ophthalmic examination was done to exclude visual or hearing problems. Psychometric evaluation was performed using the Stanford-Binet test [25] for determination of mental age. Arabic dyslexia assessment test [26] was conducted to assess the presence or absence of associated dyslexia. The test of Mathematical AbilitiesThird Edition (TOMA-3) was translated and modified to suit the Egyptian school-age children who have a mathematical disability. A pilot study was carried out on 8 normal and 8 dyscalculic pupils to ensure the suitability of the test elements before applying them to large numbers of pupils, and to test its reliability through testretest administration. After that, the translated, modified version was administered to apply it on all candidates in both groups.

\section{Statistical analysis}

Data were collected and entered into the computer using SPSS (Statistical Package for Social Science) program for statistical analysis (ver. 21) [27]. Data were entered as numerical or categorical, as appropriate.

Reliability of the modified test was measured by the following: (a) Test-retest reliability was carried upon 16 pupils (8 normal and 8 dyscalculic). These pupils were subjected twice to the test items. The degree of similarity between the two test scores indicates the amount of stability possessed by the test. (b) Coefficient alpha reliability demonstrated the internal consistency associated with scores. It was measured using Cronbach's alpha analysis.

Validity was measured by (a) content description validity that was used to test the degree to which the instrument has an appropriate sample of items for the construct being measured and (b) construct validity which means that a test designed to measure a particular construct is actually measuring that construct.

Sensitivity and specificity were done using the receiver operating characteristic (ROC) curves and area under the ROC curve (AUC) which are a measure of the overall performance of a diagnostic test and are interpreted as the average value of sensitivity for all possible values of specify.

\section{Results}

By comparing the results of normal and affected groups, we concluded that the dyscalculic group performed worse compared with the control group regarding all items of the core subtest of modified TOMA-3, and the difference between the two groups was statistically significant.

Test-retest reliability showed that there was no significant difference between initial and retest scores, which 
indicated the modified test had a high degree of reliability (Figs. 1 and 2). Additionally, the Cronbach's alpha value was 0.915 , which indicates an excellent degree of reliability for raw score. The high values of it in all subtest items denoted significant inter-correlation between test items, which indicated the satisfactory level of internal consistency of this test. Regarding the validity of the test, it was measured by content description validity. The test was assessed by 7 expert phoneticians who checked that the test included all relevant and important items. By computing a content validity index (depending on rating of item relevance by content experts), the results showed that the modified version of the test had an excellent content validity index. Construct validity was also measured, and the result showed that there was a significant positive correlation between all scale items which indicated that all items nearly measure the same construct (scale outcome variable). Furthermore, sensitivity and specificity were measured by calculation of the receiver operating characteristic (ROC) curves and AUC, the result demonstrated that the sum of scaled score was a statistically significant discriminator of dyscalculic from non-dyscalculic pupils, with a cutoff point of $\leqq 33$ (Fig. 3).

\section{Discussion}

Dyscalculia is a common learning issue that impacts children's ability to do math. Failure to identify the disorder early enough for early intervention leads to a bad impact on our children's daily life that requires mathematical ability. The TOMA-3 was developed in response to the requirement for a test that diagnoses dyscalculia. In the present study, we formulated a modified Arabic

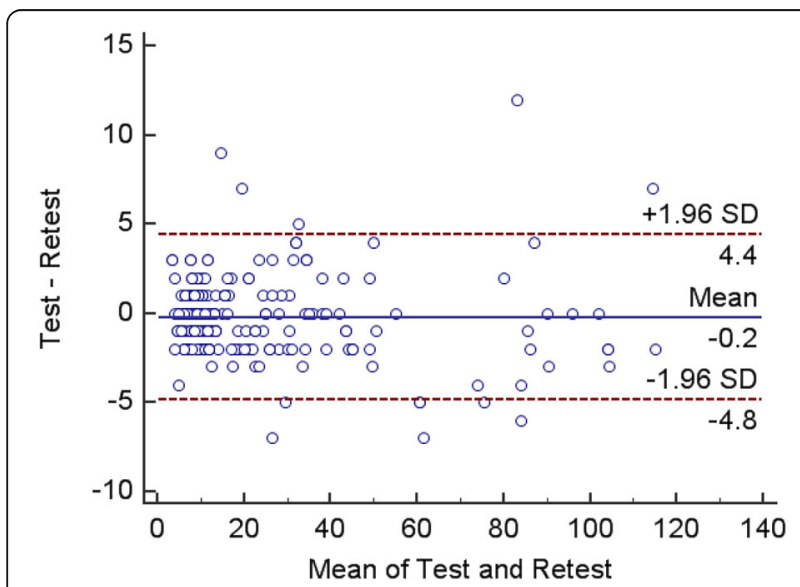

Fig. 1 Bland and Altman plot for agreement showing narrow margin of bias from upper limit (4.40) and lower limit (-4.83) to the arithmetic mean difference of test and retest measurements, which indicate an excellent degree of reliability. Blue line indicates mean difference. Dashed red line indicates 95\% confidence interval of difference

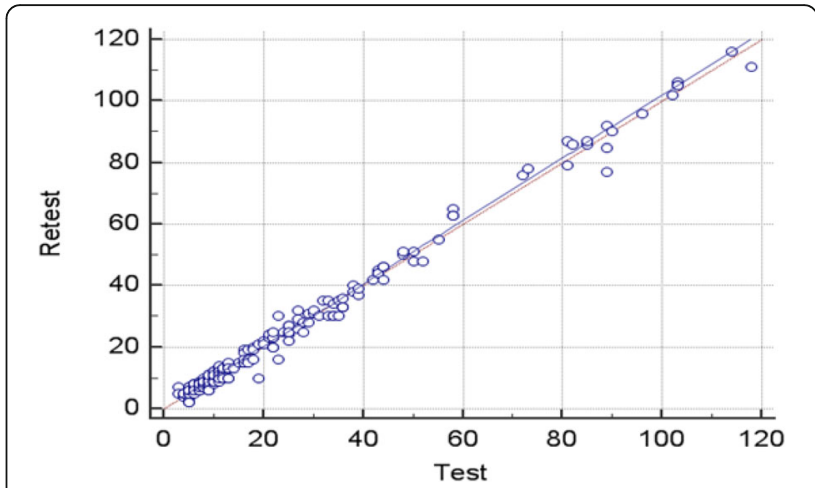

Fig. 2 Scatter diagram for concordance correlation coefficient showing that there was no significant deviation from the $45^{\prime}$ line of concordance, which indicate almost perfect degree of reliability. Red line indicates line of equality. Blue line indicated the trend line (loess smoothing) (span 80\%)

version of this test to diagnose Egyptian children who have mathematic disabilities. In fact, TOMA3 is considered a trial to expand arithmetical evaluation beyond ordinary skills [28]. It has 4 core subtests and a single supplementary test. The rationale for choosing this is as follows [24]: Mathematical Symbols and Concepts: It provides a wide sampling of the signs symbols and vocabulary items that students need to decode as they read and study mathematics in school settings. In the present study, the mean and SD of raw scores were higher in the normal group $(24 \pm 9)$ compared with the dyscalculic group $(9 \pm 4)$. This may be due to the fact that these children have a poor visual memory, causing them to

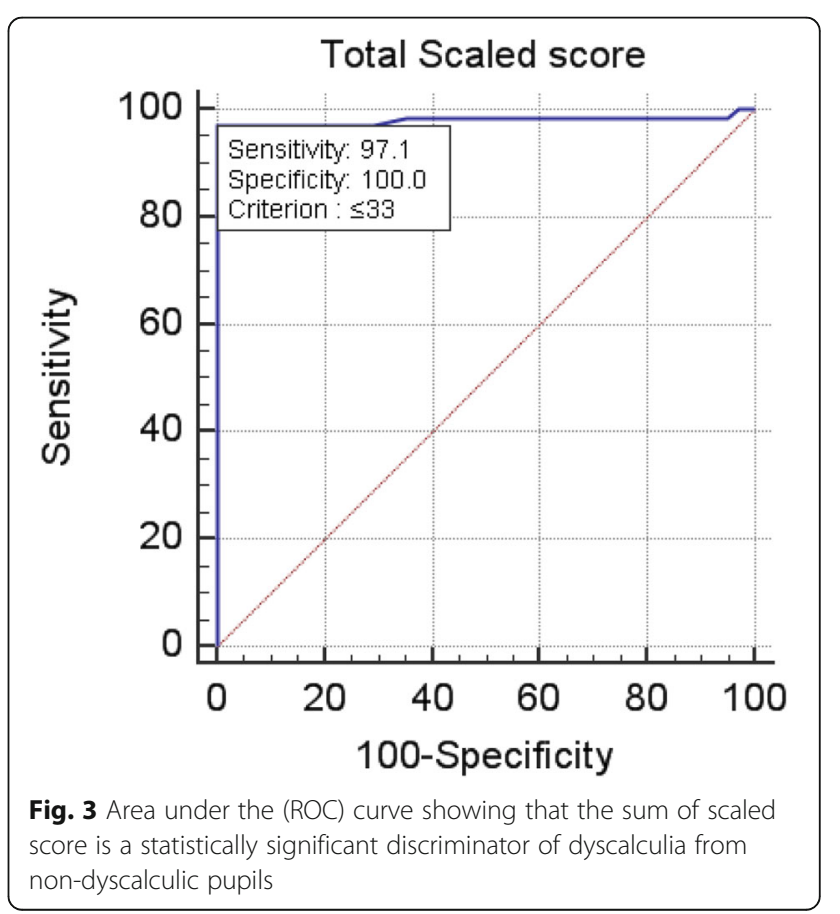


have a difficulty in connecting abstract symbols to their numerical magnitude or seeing the connection for instance between five fingers and the number five. It is similar to kids with dyslexia, who have a difficulty connecting sounds with letters [29]. Computation: It is widely used in mathematics education and its assessment [30]. In the current study, the mean of raw scores was significantly higher in the normal group $(22 \pm 7)$ than dyscalculic groups $(11 \pm 4)$. Many children with dyscalculia have intentional-sequential deficit [31]. In numerical computations, very fine details, such as the precise location of decimal points and differences in operational signs, are important for successful completion of the task. Computation requires students to mobilize and sustain an adequate level of attention while working from textbooks, copying from the board, or monitoring their own work. The previous operations tend to be impaired in children with learning and attention problems. Mathematics in Everyday Life: The application of mathematical content to community living and to professional life is an implicit goal of mathematics instruction. In our study, the mean of raw scores in the normal group was $(19 \pm 6)$, compared to $(8 \pm 6)$ in the dyscalculic group. This result was likely attained due to the fact that most of the affected children had visual-spatial attention deficits, which may be related to visuo-spatial working memory dysfunction [32]. Spatial processes can be potentially important in mathematics, where explicit visualization is required, like when imagining operations along the number line or visualizing functional relationships. So children with DD have bad scores on answering questions that are concerned with the geometrical shapes, judging distances between objects, measure quantities, telling the estimated time, and estimating costs. These examples represent the most common examples of mathematical applications in daily life. Word Problems: It was designed to provide practice with the practical calculations needed for various occupations or trades. In the present study, the mean raw score of this subtest in the normal group was $(15 \pm 5)$, compared to $(6 \pm 3)$ in the dyscalculic group. It is due to the fact that the solution of these problems depends on the student's ability to retrieve the numerical information that has been saved before in memory and on the ability to pay sustained attention to solve the successive steps of them. Unfortunately, these educational factors are affected in dyscalculic pupils, thus lowering their mathematical performance. Attitude toward Math: This subtest is a selfreport scale which gives an idea about pupil's attitudes that might or might not be related to their measured progress in mathematics. In our study, the mean raw score was $43 \pm 6$ in the normal group, which was significantly higher than the dyscalculic groups $(36 \pm 8)$. Mastery of arithmetic skills predicts one's educational outcomes as well as his impression toward mathematics [33]. Poor attitudes resulting from weak arithmetic abilities negatively affect the student's motivation to engage in math instruction.

Actually, there was a statistically significant difference between the control and dyscalculic group regarding all items of the Arabic version of the test. We thought it was attributed to the fact that impairment of cognitive functions (such as working memory processing dysfunction and poor attention, as well as visual-spatial skills deficit) was considered the main cause of this imbalance. All of these cognitive abilities have been linked to the IPS, and thus its deficit indicated abnormality of that area in DD [34].

\section{Test-retest reliability}

In the current study, test-retest reliability was carried on 16 pupils ( 8 normal and 8 dyscalculic) of both sexes between the age of 8 to 18 years. The result showed that average measures of intraclass correlation coefficient (ICC) were 0.9977 (excellent degree of reliability), and the concordance correlation coefficient $=0.9954$ (almost perfect degree of reliability). This result proved that the formulated test was highly reliable for Egyptian dyscalculic children.

\section{Coefficient alpha reliability}

The Cronbach's alpha value was 0.91 (excellent reliability) for total raw score.

Regarding content validity, the Arabic version of the TOMA-3 test had high satisfaction from seven Egyptian expert phoneticians in Alexandria University. By computing a content validity index, the result demonstrated that modified version of the test had an excellent content validity index

\section{Construct validity}

Correlation coefficient of the core subtests ranged from 0.39 to 0.96 . Therefore, the result also showed that there was a significant positive correlation between all scale items which indicated that all items nearly measured the same construct.

Regarding sensitivity and specificity, the ROC curve and AUC of total scaled score $=0.98$ (an excellent degree of accuracy), with a sensitivity of $(97.14 \%)$, and specificity of (100.00\%). Therefore, the sum of the scaled score was the most accurate to discriminate between dyscalculic and non-dyscalculic pupils.

\section{Conclusion}

The Arabic version of TOMA-3 test is highly valid and reliable for diagnosis of dyscalculia in Egyptian pupils. 


\section{Abbreviations}

TOMA-3: Test of Mathematical Abilities—Third Edition; DD: Developmental dyscalculia; ADHD: Attention Deficit Hyperactivity Deficit; ICC: Intraclass correlation coefficient; ROC: Receiver operating characteristics; AUC: Area under the curve; IPS: Intra-parietal sulcus

\section{Acknowledgements}

The authors acknowledge all study participants.

\section{Authors' contributions}

RMA gave the idea, supervised the stages of the research, and helped with study design. $\mathrm{NHH}$ put the study design and wrote the paper. AMF collected the data and followed the cases. They all approved the final version of the manuscript.

\section{Funding}

This study received no funding

\section{Availability of data and materials}

The datasets used and/or analyzed during the current study are available from the corresponding author on reasonable request.

\section{Ethics approval and consent to participate}

This study was approved by the Research Ethics Committee of the Faculty of Medicine-Alexandria University in Egypt on 18 October 2017; Reference Number of approval: 0105217. All parents of patients included in this study gave written informed consent to participate in this research.

\section{Consent for publication}

Not applicable.

\section{Competing interests}

The authors declare that they have no competing interests.

Received: 12 June 2020 Accepted: 19 June 2020

Published online: 28 September 2020

References

1. Biembengut MS, Hein N (2000) Mathematical modeling in teaching. Context, São Paulo, pp 9-16

2. Skagerlund K, Träff U (2016) Number processing and heterogeneity of developmental dyscalculia: subtypes with different cognitive profiles and deficits. J Learn Disabil 49:36-50

3. Shalev RS, Gross-Tsur V (2001) Developmental dyscalculia. Pediatr Neurol 24: 337-342

4. $\quad$ Trott C (2009) Dyscalculia. In: Pollak D (ed) Neurodiversity in higher education: positive responses to specific learning differences. John Wiley, Chichester

5. Geary DC (1993) Mathematical disabilities: cognition, neuropsychological and genetic components. Psychol Bull 114:345-362

6. Geary D, Bailey D, Hoard M (2009) Predicting mathematical achievement and mathematical learning disability with a simple screening tool. J Psychoeduc Assess 27:265-279

7. Träff U, Olsson L, Östergren R, Skagerlund K (2017) Heterogeneity of developmental dyscalculia: cases with different deficit profiles. Front Psychol 7:2000

8. Landown R (1978) Retardation in mathematics: consideration of multifactorial determination. Journal of Child Psychology and Psychiatry 19:181185

9. Fletcher J (2007) Learning disabilities: from identification to intervention. New York: Guilford.:217-225

10. Ashish R, Elizabeth I, Caroline E, Mary R, Julie L (2013) Developmental trajectories of grey and white matter in dyscalculia. Trends Neurosci 2:56-64

11. Szucs D, Devine A, Soltesz F, Nobes A, Gabriel F (2013) Developmental dyscalculia is related to visuo-spatial memory and inhibition impairment. Cortex 49:2674-2688

12. Ronald LL, Terry T. Melvin DL, Pasquale JA. Impact of attentional dysfunction in dyscalculia. Dev Med Child Neurol 1999:41:639-642.

13. Sherman A, Edelman MW, Solow RM (1994) Children's Defense Fund. Wasting America's future. The Children's Defense Fund report on the costs of child poverty. Beacon Press, Boston
14. von Aster MG, Shalev R (2007) Number development and developmental dyscalculia. Dev Med Child Neurol 49:868-873

15. Willcutt EG, Petrill SA, Wu S, Boada R, Defries JC, Olson RK et al (2013) Comorbidity between reading disability and math disability: concurrent psychopathology, functional impairment, and neuropsychological functioning. J Learn Disabil 46:500-516

16. GrossTsur V, Manor O, Shalev RS (1996) Developmental dyscalculia: prevalence and demographic features. Dev Med Child Neurol 38:25-33

17. Ao LK, von Aster M (2012) The diagnosis and management of dyscalculia. Dtsch Arztebl Int 109(45):767-778

18. Kaufmann L, von Aster M (2012) The diagnosis and management of dyscalculia. Dtsch Arztebl Int 109(45):767-778

19. Toll SW, Van der Ven SH, Kroesbergen EH, Van Luit JE (2011) Executive functions as predictors of math learning disabilities. J Learn Disabil 44:521532

20. Hoard MK, Geary DC, Hamson CO (1999) Numerical and arithmetical cognition: performance of low- and average-IQ children. Mathematical Cognition 5:65-91

21. Wechsler D (1992) The psychological corporation, 3rd edn. Sidcup, Kent, UK Wechsler Intelligence Scale for Children

22. Connolly AJ (2007) KeyMath 3: diagnostic assessment. San Antonio, TX, Pearson

23. Butterworth B (2003) Dyscalculia screener. NferNelson Pub, London, p 80

24. Brown VL, Cronin ME, Bryant DP (2012) Test of mathematical abilities, 3rd edn. Austin, TX, Pro-Ed

25. مقياس ستانفورد بينيه الصورة الر ابعة اقتباس واعداد دكتور لوبس كامل مليكة الطبعة الثانبة مطبعة

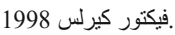

26. Aboras Y, Abdou R, Kozou H (2008) Development of an Arabic test for assessment of dyslexia in Egyptian Children. Bulletin of Alexandria, Faculty of Medicine, pp 653-662

27. Corp IBM (2012) IBM SPSS Statistics for Windows, Version 21.0. Armonk. IBM Corp, NY

28. Mcloughlin JA, Lewis RB (1990) Assessing special students. Merrill Macmillan New York, NY, p 347

29. Szücs D, Team the University of Cambridge. Mathematical-difficultiesrelated-to-poor-visual-perception-and-memory. 2013. Available at: https://www.edubloxtutor.com/mathematical-difficulties-related-to-poorvisual-perception-and-memory.

30. Reston AV. Principles and standard for school mathematics: Content standards and grade level competencies. National Council of Teachers of Mathematics (NCTM); 2000

31. Badian NA (1983) Dyscalculia and nonverbal disorders of learning. In: Myklebust HR (ed) Progress in learning disabilities, vol 5. Grune and Stratton, New York, pp 235-264

32. B.P. Rourke, J.A. Conway. Disabilities of arithmetic and mathematical reasoning: perspectives from neurology and neuropsychology.Journal of Learning Disabilities 1997;30: 34-46.

33. Ritchie SJ, Bates TC (2013) Enduring links from childhood mathematics and reading achievement to adult socioeconomic status. Psychol Sci 24:1301-1308

34. Dumontheil I, Klingberg T (2011) Brain activity during a visuospatial working memory task predicts arithmetical performance 2 years later. Cerebral Cortex 22:1078-1085

\section{Publisher's Note}

Springer Nature remains neutral with regard to jurisdictional claims in published maps and institutional affiliations. 